\title{
Comparative effectiveness of bioassay methods in identifying the most virulent entomopathogenic fungal strains to control Bemisia tabaci (Gennadius) (Hemiptera: Aleyrodidae)
}

\author{
Satish Kumar Sain ${ }^{1 *}$ D, Dilip Monga ${ }^{1}$, Rishi Kumar ${ }^{1}$, Dipak T. Nagrale ${ }^{2}$, Sandhya Kranthi ${ }^{2}$ and Keshav Raj Kranthi ${ }^{3}$
}

\begin{abstract}
Bemisia tabaci (Gennadius) (Hemiptera: Aleyrodidae) is a serious pest of cotton that inflicts huge economic losses. Excessive use of chemical pesticides for its management causes environmental pollution and pesticide resistance. Six bioassay methods and ten entomopathogenic fungal strains (EPFs) were evaluated to find out the suitable bioassay method and the most virulent strain(s) for management of B. tabaci under laboratory and polyhouse conditions. The highest tenderness and survival period (> 30 days) of the leaves and increasing trend in nymphal mortality was recorded in a new modified polyhouse bioassay method (NMPBM). NMPBM was found to be effective, simpler, and less labor intensive for evaluating large numbers of EPF strains. Twelve newly isolated EPF strains were characterized based on their morphological and molecular characteristics. The highest whitefly nymphal mortality (at

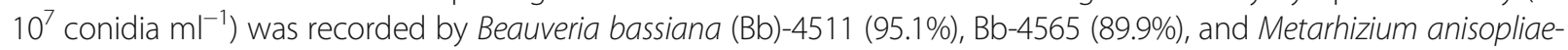
1299 (86.7\%) at the seventh day post inoculation. However, the overall bioefficacy index was higher in Bb-4511 (78.1\%), Cordyceps javanica (Cj)-102 (77.0\%), and Cj-089 (75.4\%) than other EPF strains. The lowest values of LC 50 and LC 90 were with $\mathrm{Cj-}-089$ and Bb-4511. The field deployment of effective formulation of these most virulent EPF strains might be helpful for managing B. tabaci populations and CLCUD incidence under insecticide resistance management programs.
\end{abstract}

Keywords: Bemisia tabaci, Bioassay methods, Entomopathogenic fungi, Whitefly, Virulence

\section{Background}

Whitefly Bemisia tabaci (Gennadius) (Hemiptera: Aleyrodidae) is a polyphagous pest of more than 900 plant species, and is able to transmit more than 110 plant viruses worldwide (Jones 2003; Sadeh et al. 2017). It adapts to new host plants and diverse geographical regions easily. Its presence has now been reported from all the continents, except Antarctic (Hsieh et al. 2006). It is also a serious threat to cotton production, because it causes direct damage to the crop and transmits cotton leaf curl disease (CLCuD). The range of yield loss due to CLCuD was reported to be from 81.4 to $88.4 \%$ in all

\footnotetext{
*Correspondence: sain.skumar@gmail.com

${ }^{1}$ ICAR- Central Institute for Cotton Research, Regional Station, Sirsa, Haryana, India

Full list of author information is available at the end of the article
}

northern cotton growing states of India (Monga 2014). Until now, five whitefly outbreaks have been noticed in cotton growing states in India. During 2015-2016, a severe whitefly outbreak was also experienced in the northern cotton growing zone of India (Kranthi 2015).

Chemical control is the dominant management approach for $B$. tabaci in diverse agricultural production systems. Thirty-five insecticides, including six mixtures have been registered so far for whitefly management in India, even though it has developed resistance to more than 40 active ingredients of insecticides (Basit et al. 2013). Considering the economic impact and reduced susceptibility to several insecticides, the use of environmentally friendly and sustainable approaches for its control is under research, including integrated pest management (IPM) and insecticide resistance management (IRM) studies. Several 
studies indicated that more than 20 species of entomopathogenic fungi (EPF) can infect whiteflies (Scorsetti et al. 2008). Beauveria bassiana (Bals-Criv.) Vuill, Cordyceps farinosa (Holmsk.) Fr. (formerly Isaria farinosa), and Metarhizium anisopliae (Metschn.) Sorok. (Hypocreales: Clavicipitaceae) are the potential EPF for B. tabaci (Faria and Wraight 2001; Lacey et al. 2008). Although, considerable studies were done in North America, Europe, and North Eastern Asia (Faria and Wraight 2001; Lacey et al. 2015), but in India, so far only Lecanicillium lecanii R. Zare \& W. Gams (Hypocreales: Clavicipitaceae) is available for whitefly management out of 115 commercial products registered and recommended for cotton pest management in India (Anon. 2019).

The aim of this study was to evaluate the most effective and virulent EPF strains, which can further be utilized to develop an eco-compatible and effective bioformulation for reducing the whitefly populations and $\mathrm{CLCuD}$ incidence in the field through an IPM/IRM program.

\section{Materials and methods}

Survey sites, sample collection, and isolation of fungal pathogens

Field surveys were conducted in three upland cotton growing states of North India from April to November 2016. Whitefly samples (adults and nymphs) (Asia-II-1) showing visible symptoms of fungal infection (20X hand lens) on cotton, vegetables, and weeds were collected from Punjab, Haryana, and Rajasthan states of India. Samples were surface sterilized, and plated individually in sterilized Petri-dishes containing Sabouraud Dextrose Agar (Hi Media) media amended with $0.2 \%$ yeast (SDYA), and streptomycin sulfate $\left(20 \mu \mathrm{g} \mathrm{L}^{-1}\right)$. Fresh fungal colonies were transferred to the Petri-dishes containing fresh SDYA and incubated for 1015 days at $\left(28 \pm 2{ }^{\circ} \mathrm{C}\right)$ in the dark. For transferring pure culture, conidia were directly scraped from the surface of the primary culture, using a sterile platinum loop.

\section{Morphological characterization of EPF isolates}

Pure cultures were identified, using identification keys and relevant literature (Humber 2012). In addition to the isolates, collected through survey, fungal isolates were purchased from Microbial Type Culture Collection (MTCC), Chandigarh (India), National Agriculturally Important Microbial Culture Collection Center (NAIMCC), Uttar Pradesh (India) and maintained on SDYA for further studies (Table 1). All these EPF isolates were evaluated against whitefly nymphs to find out the most virulent ones.

\section{Molecular characterization of EPF isolates}

The molecular characterization was done only for 12 newly isolated EPF. The extraction of DNA from each strain was done, using PowerLyzer ${ }^{\circ}$ UltraClean $^{\circ}$
Table 1 Entomopathogenic fungal isolates used in this study

\begin{tabular}{ll}
\hline Fungal isolates & Culture collection accession no. \\
\hline Beauveria bassiana-4565 & MTCC-4565 \\
Beauveria bassiana-4511 & MTCC-4511 \\
Beauveria bassiana-4543 & MTCC-4543 \\
Beauveria bassiana-6097 & MTCC-6097 \\
Beauveria bassiana-4121 & MTCC-4121 \\
Beauveria bassiana-6095 & MTCC-6095 \\
Metarhizium anisopliae-1299 & NAIMCC-F-1299 \\
Beauveria bassiana-403 & NAIMCC-F-403 \\
Beauveria bassiana-409 & NAIMCC-F-409 \\
\hline
\end{tabular}

Microbial DNA isolation Kit (MO BIO Laboratories, Inc., USA). Approximately 550-600 bp internal transcribed spacer (ITS) region of all genomic DNA samples were amplified, using universal primer forward (ITS1) 5'-TCCGTAGGTGAACCTGCGG-' 3 and reverse primer (ITS4) 5'-TCCTCCGCTTATTGATATGC-' 3 in a thermocycler (Eppendorf-Master cycler, Nexus Gradient, Germany) (White et al. 1990). The PCR reactions were performed in a total volume of $25 \mu \mathrm{l}$, which contained (2.5 $\mu \mathrm{l}$ of $10 \mathrm{X})$ Taq polymerase buffer, $(1.5 \mu \mathrm{l}$ of $25 \mathrm{mM})$ $\mathrm{MgCl}_{2},(0.5 \mu \mathrm{l}$ of $10 \mathrm{mM})$ dNTP's, $(0.5 \mu \mathrm{l})$ of Taq polymerase, $(18 \mu \mathrm{l})$ of double-distilled $\mathrm{H}_{2} \mathrm{O}, 10 \mu \mathrm{M}$ of forward and reverse primer each, and $(1 \mu \mathrm{l})$ of the rDNA sample. The amplification of rDNA was done with an initial denaturation at $94{ }^{\circ} \mathrm{C}$ for $4 \mathrm{~min}, 35$ cycles of denaturation at $94{ }^{\circ} \mathrm{C}$ for $35 \mathrm{~s}$, annealing at $57{ }^{\circ} \mathrm{C}$ for $1 \mathrm{~min}$, extension at $72{ }^{\circ} \mathrm{C}$ for $3 \mathrm{~min}$, and a final extension at $72{ }^{\circ} \mathrm{C}$ for $10 \mathrm{~min}$, followed by a halt at $4{ }^{\circ} \mathrm{C}$ for $5 \mathrm{~min}$. PCR products were separated in $1.5 \%$ agarose gel stained with $0.5 \mu \mathrm{g} \mathrm{ml}^{-1}$ ethidium bromide. The amplified PCR products were then eluted, using Exo-SAP IT PCR Cleanup (Affymetrix USB, US) and sequencing was done through Eurofins Genomics India Pvt. Ltd. India. The chromatogram quality of sequences was checked by Applied Biosystems Sequence scanner v 1.0 software. The contigs were formed by the CAP3 sequence assembly program from respective forward and reverse sequences of isolates (Huang and Madan 1999), and compared with the available database at the National Center for Biotechnology Information (NCBI) BLASTn similarity search.

\section{Rearing of whitefly and egg laying}

Whitefly adults (Asia-II-1 populations) were collected from the research farm of ICAR- Central Institute for Cotton Research-Regional Station $\left(29^{\circ} 32^{\prime} 36.1^{\prime \prime} \mathrm{N} 75^{\circ}\right.$ $\left.02^{\prime} 18.8^{\prime \prime} \mathrm{E}\right)$. They were released on potted cotton plants (HS-6 variety) in polyhouse $\left(28 \pm 2{ }^{\circ} \mathrm{C}\right.$ and $70-80 \%$ relative humidity $(\mathrm{RH})$ ), under a diurnal day/night cycle of 16/8 h (Naveen et al. 2017). Whitefly adults' population 
reached about 80-100/leaf after 1 month. For maintaining a fresh population of the whitefly adults, aseptically grown 1-month-old potted cotton plants were placed in a polyhouse, at an interval of 15 days. For large-scale bioassay tests, pots with pest free 30 -day-old plants, with 5-6 primary leaves were placed near the infested plants for $24 \mathrm{~h}$. This procedure provided approximately 50-80 nymphs/leaf. The adults were gently removed from infested plants and the pots were transferred to another screen-house for 10 days, until nymphs reached the second instar (0.30-0.44 $\mathrm{mm}$ in length and 0.18-0.36 mm in width) (Mascarin 2013). Subsequently, these plants were used for screening of EPF strains.

\section{Preparation of fungus inoculum}

The EPF cultures were incubated on SDYA in sterilized Petri-dishes for $12-15$ days $\left(28 \pm 2{ }^{\circ} \mathrm{C}\right)$ in darkness. Conidia were harvested by flooding the media with a sterile $0.01 \%(v / v)$ Tween 20 (PEG-20 sorbitan monolaurate, Hi Media), and stirring with a glass rod. The suspension was vortexed for $2 \mathrm{~min}$ and filtered through double layers of nylon cheesecloth. The suspension was vortexed for $1 \mathrm{~min}$ before spray inoculation bioassay. In all bioassays, conidial concentration of $1 \times 10^{7}$ conidia ml $\mathrm{ml}^{-1}$ was utilized. Before the onset of bioassay, the viability/ germination of conidia on SDYA medium was confirmed (>95\% with $24 \mathrm{~h}$ post inoculation at $28 \pm 2{ }^{\circ} \mathrm{C}$ ), using compound microscope ( $\times 400$ magnification).

\section{Standardization of bioassay techniques}

To start the EPF screening biaoassy, the in vitro bioassay methods (leaf disc and detached leaf) were tried, but we could not be able to perform the bioassay up to 7 days. The problem of leaf survival was found for conducting screening bioassay for a period of 7-10 days. Further, the IRAC method no: 016 for evaluation of EPF against the whitefly nymphs (IRAC 2009b) was tried, but it was more labor and time consuming. Therefore, five laboratory bioassay methods and a newly modified polyhouse bioassay method (NMPBM) were compared for their comparative effectiveness:

\section{Leaf disc method}

Fresh cotton leaf discs (20 mm diam.), containing 10-15 fresh nymphs [10 days after egg laying (DAE)], were used for bioassay (Mascarin 2013). Leaf-discs were dipped into the freshly prepared conidial suspension $\left(1 \times 10^{7}\right.$ conidia $\left.\mathrm{ml}^{-1}\right)$, separately and air dried. Discs were placed upside down onto $0.2 \%$ plain water agar medium in Petri plates, sealed with parafilm, and incubated at $28 \pm 2{ }^{\circ} \mathrm{C}$. In control treatment, leaf discs were dipped into $0.02 \%$ Tween 20 solution. Each treatment was replicated thrice having three Petri-dishes with three discs each.

\section{Detached leaf method $A$}

In this method, fully expanded excised leaves, containing 40-50 fresh nymphs/leaf (10 DAE), were used (Mascarin 2013). Excised leaves were dipped into a conidial suspension $\left(1 \times 10^{7}\right.$ conidia $\left.\mathrm{ml}^{-1}\right)$ individually and air dried. Later, they were placed on to the $0.2 \%$ plain water agar media in $100 \mathrm{~mm}$ breeding disc keeping the ventral surface up and incubated at $28 \pm 2{ }^{\circ} \mathrm{C}$. In control treatment, leaves were dipped into $(0.02 \%$ Tween 20 solution) and air dried. Each treatment was replicated thrice. One replicate consisted of three breeding disc with one leaf each.

\section{Detached leaf method $B$}

Fully expanded excised leaves along with petioles were used (Cuthbertson et al. 2005; Eslamizadeh et al. 2015). The cut petioles were dipped into $0.2 \%$ sucrose solution in $5 \mathrm{ml}$ plastic vial and sealed with parafilm. Subsequently, $2 \mathrm{ml}$ fresh EPF conidial suspension $\left(1 \times 10^{7}\right.$ conidia $\mathrm{ml}^{-1}$ ) was applied to $40-45$ nymphs on each leaf with a commercial hand sprayer. Leaves were air dried and placed with ventral surface up into breeding disc lined with a double layer of moist filter paper. Three replicates of each treatment were maintained at $28 \pm 2^{\circ}$ $\mathrm{C}$ and $80 \pm 4 \% \mathrm{RH}$. One replicate comprised of three breeding discs with one leaf each. In control treatment, leaves were sprayed by $0.02 \%$ Tween 20 solution.

\section{Detached leaf method C}

Unlike detached leaf method B, a $15 \mathrm{ml}$ glass vial sealed with parafilm was used to support the excised leaf (IRAC 2009a, 2009c). Conidial suspension $\left(1 \times 10^{7}\right.$ conidia $\mathrm{ml}^{-1}$ ) was applied on each leaf with a hand sprayer and air dried. Then treated leaf along with the glass vial was placed in transparent plastic cups of (15 cm height) and covered with muslin cloth. In control treatment, leaves were sprayed by $0.02 \%$ Tween 20 solution. Each treatment comprised of three replications with three plastic cups each.

\section{Detached leaf method D}

Potted cotton plants having fully expanded leaves with 40-50 fresh nymphs (10 DAE) on each leaf were utilized in this method (IRAC 2009b). Two milliliter conidial suspension per leaf $\left(1 \times 10^{7}\right.$ conidia $\left.\mathrm{ml}^{-1}\right)$ was applied by a hand sprayer. Marked leaves were air dried and detached from each plant and placed on the $30 \times 30 \times$ $10 \mathrm{~cm}$ size sterilized plastic trays, containing $0.2 \%$ sucrose solution. To keep the leaves erect, an aluminum mesh was placed at the middle of it. In control treatment, leaves were sprayed by $0.02 \%$ Tween 20 solution. Three replications of each treatment with six leaves in each were maintained. 


\section{New modified polyhouse bioassay method}

The IRAC susceptibility test methods series no: 016 suggested to use potted cotton plant, on which leaves were trimmed into a small rectangle (three leaf squares with $(4 \times 6 \mathrm{~cm}$ size each), using scissors. The plants were placed within a ventilated holding cage (approx. $50 \times$ $50 \times 50 \mathrm{~cm})$ at $\left(20{ }^{\circ} \mathrm{C}, 60 \%\right.$ relative humidity and $16.8 \mathrm{~h}$ lighting regime) (IRAC 2009b). The whitefly adults were transferred to the cages (50-70 insects per leaf), using an aspirator and left for $24 \mathrm{~h}$ for egg laying, after which all the adults were removed from the cage. This IRAC method seems to be labor intensive, time consuming, and expensive too. Hence, in this new modified polyhouse bioassay method (NMPBM), we have slightly modified IRAC 016. In NMPBM, aseptically gown 1-month-old potted cotton plants (4-5 fully expanded leaves) were used. Potted plants (without leaf trimming) were kept inside a whitefly rearing polyhouse containing whitefly infested plants (30-40 adults per leaf) for $24 \mathrm{~h}$. After egg laying, whitefly adults were removed gently from plants, using air pressure of hand sprayer and transferred aseptically in another polyhouse (at 33.7$26.7^{\circ} \mathrm{C}$ Max. Mini Temp and 80.3-68.4\% RH). Later, 10 DAE, the nymphs were marked on the underside of the leaf by a water proof marker (30-40 nymphs per leaf). Conidial suspension $\left(1 \times 10^{7}\right.$ conidia $\left.\mathrm{ml}^{-1}\right)$ was applied to nymphs by a hand sprayer at a volume of $10 \mathrm{ml} /$ plant ( $2 \mathrm{ml} /$ leaf $)$. Control leaves were sprayed by $0.02 \%$ Tween
20 solution. Each treatment was replicated thrice and each replicate consisted of three plants with three leaves (Fig. 1).

All the detached leaf bioassays were carried out in the laboratory at $28 \pm 2{ }^{\circ} \mathrm{C}$ with a $16: 8 \mathrm{~h}$ (L:D) photoperiod. Four fungal cultures (MTCC-4121, MTCC-6095, NAIMCC-403; NAIMCC-409) along with the control were evaluated in all the methods for comparison. In all bioassay methods, mortality of nymph and leaf survival were recorded at 3, 5, and 7 days post inoculation (DAI), using a 20X hand lens. Nymphs were considered alive if they were opaque or whitish green and shiny with eyes or visible honeydew droplets appearing on the excretions. They were considered dead if their bodies were yellowish-brown matt and shriveled. Microscopic observations were carried out to confirm the fungal infections. They were also placed onto the $0.2 \%$ plain water agar to observe fungal growth.

\section{Bioassays against whitefly nymphs}

A total of ten EPF strains were evaluated for their comparative virulence against the 10-day-old $B$. tabaci nymphs (second to third nymphal instars), using NMPBM. Ten milliliter conidial suspension of each EPF $\left(1 \times 10^{7}\right.$ conidia $\left.\mathrm{ml}^{-1}\right)$ was applied onto cotton plant leaves ( $\sim 2 \mathrm{ml} /$ leaf) infested with $40-50$ nymphs, using a hand-held sprayer. Three replicates were maintained by three plants each (three leaves/plant). Inoculated plants

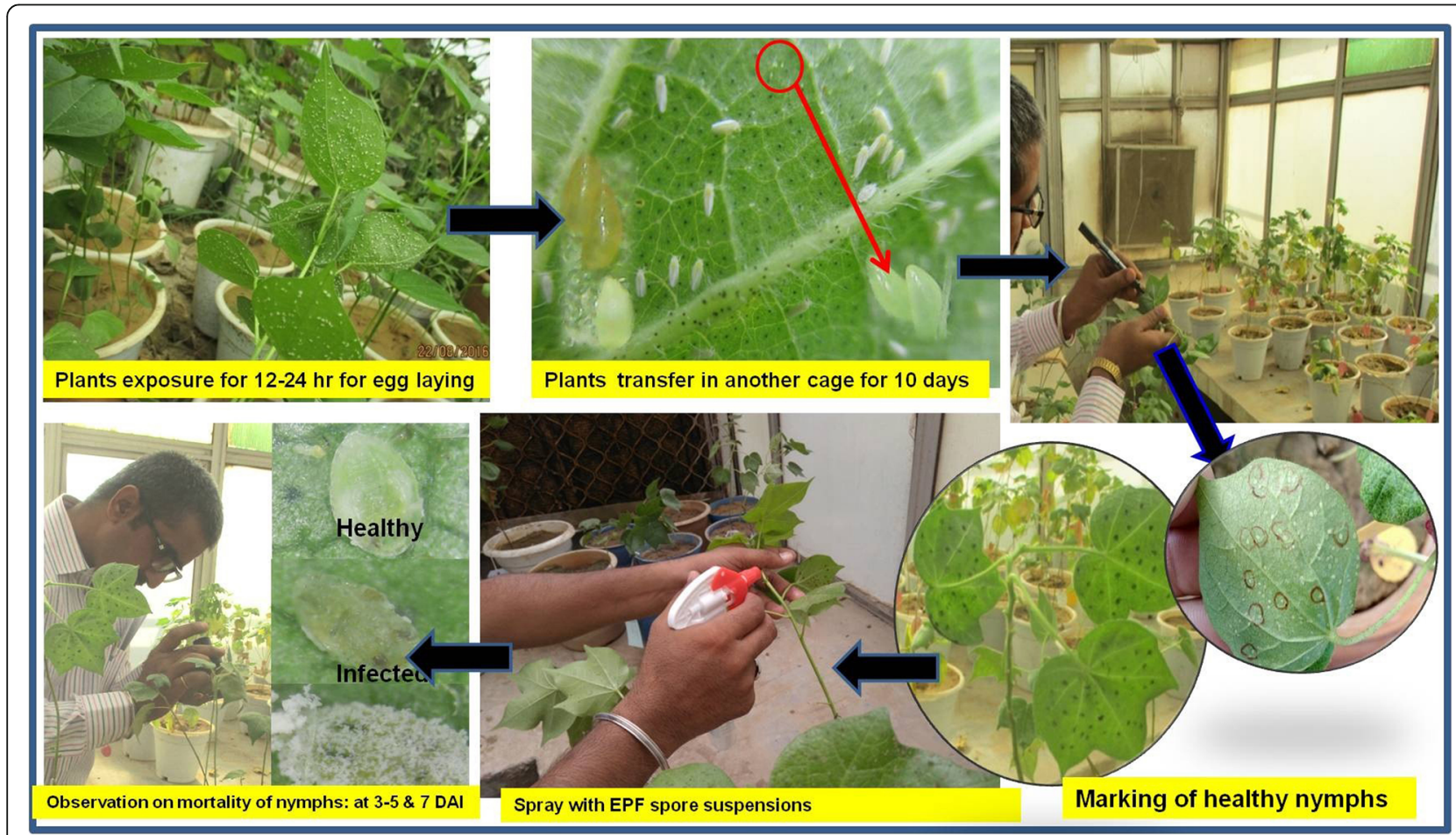

Fig. 1 New modified polyhouse bioassay method for screening of virulence in entomopathogenic fungal isolates against whitefly nymphs 
were kept in polyhouse at $80 \pm 4 \% \mathrm{RH}$ and $28 \pm 2{ }^{\circ} \mathrm{C}$. Plants were provided by irrigation with $0.1 \%$ nitrogen-phosphorous-potassium (NPK). Mortality rates of whitefly nymphs were recorded at 3,5 , and 7 DAI in different treatments and control. To select the most virulent EPF isolates, the overall bioefficacy index (BI) was compared, using the modified formula: $\mathrm{BI}=35 \times$ (mycelial growth) $+15 \times$ (sporulation $1 \times 10^{7}$ conidia $\left.\mathrm{ml}^{-1}\right)+50 \times$ (nymphal mortality at $7 \mathrm{DAI}$ ) (Sain et al. 2017).

\section{Concentration-mortality and time-mortality bioassay}

Lethal concentrations $\left(\mathrm{LC}_{50}\right.$ and $\left.\mathrm{LC}_{90}\right)$ often most virulent EPF strains against whitefly nymphs were determined. The EPF solutions having a series of concentrations from $\left(1 \times 10^{4}\right.$ to $1 \times 10^{8}$ conidia $\left.\mathrm{ml}^{-1}\right)$ were prepared, using $0.05 \%$ Triton X-100. For each concentration, 50 nymphs were inoculated by applying the fungal conidia suspension, following NMPBM along with water as a control. Mortality rate was recorded at 3, 5, and 7 DAI. The experiment was repeated twice on different occasions, each time with 50 nymphs for each concentration and EPF strain.

\section{Statistical analysis}

Corrected Abbott's formula was used to correct the control mortality (Abbott 1925). The statistical analyses were performed, using the OP Stats (Sheoran et al. 1998). Means were separated, using $T$ test at the $5 \%$ level of significance. The effect of different EPF strains on nymphal mortality was analyzed, using one-way ANOVA for complete randomized block design. The averages of nymphal mortality percentages were compared by critical difference $(C D)$ value $(P<0.05)$. The effect of increasing conidial concentrations of the EPF strains on the proportional number of mycosed whitefly nymphs was analyzed, using a probit analysis of binomial proportions, and the lethal concentrations for $50 \%$ mortality $\left(\mathrm{LC}_{50}\right)$ and $90 \%$ mortality $\left(\mathrm{LC}_{90}\right)$ were calculated, including their 95\% fiducial limit (Finney 1952).

\section{Results and discussion}

\section{Survey, collection, and identification of EPF}

As a result of the field survey, a total of 12 representative EPF isolates were molecularly characterized out of 105 samples. Out of the 12 EPF isolates, six genus were identified including three Aspergillus spp., three Fusarium spp., two of each Cordyceps javanica, Penicillium oxalicum, and one of each Beauveria bassiana, Emericella sp. The identified sequences were submitted to the NCBI GenBank database (Table 2). In addition to the newly isolated EPF strains, other EPF strains including B. bassiana (MTCC-4567, -4511, -4543, -6097, -4121, -6095, NAIMCC-F-403, -409) and M. anisopliae
Table 2 Sequences of rDNA ITS region of entomopathogenic fungal isolates submitted to the NCBI GenBank

\begin{tabular}{lll}
\hline Organism & Strain ID & $\begin{array}{l}\text { NCBI GenBank } \\
\text { accession number }\end{array}$ \\
\hline Aspergillus oryzae & CICR-RSS-0015 & MG976235 \\
Aspergillus quadrilineatus & CICR-RSS-0044 & MG976236 \\
Aspergillus versicolor & CICR-RSS-0074 & MG976229 \\
Beauveria bassiana & CICR-RSS-0093 & MG976239 \\
Emericella sp. & CICR-RSS-0064 & MG976237 \\
Fusarium moniliformae & CICR-RSS-0083 & MG976231 \\
Fusarium sp. & CICR-RSS-0035 & MG976238 \\
Fusarium sudanense & CICR-RSS-0033 & MG976228 \\
Cordyceps javanica & CICR-RSS-0089 & MG976232 \\
Cordyceps javanica & CICR-RSS-0102 & MG976234 \\
Penicillium oxalicum & CICR-RSS-0082 & MG976230 \\
Penicillium oxalicum & CICR-RSS-0085 & MG976233 \\
\hline
\end{tabular}

(NAIMCC-F-1299) procured from MTCC, NAIMCC were used for the evaluation study (Table 1).

\section{Standardization of bioassay techniques}

The result of a comparative study of the bioassay methods showed that the nymphal mortality by all four EPF isolates were recorded in an increasing trend (up to 7 DAI), only under the NMPBM, while in the other methods the mortality trend was uneven (Fig. 2). The highest leaf tenderness and survival period was recorded in the NMPBM (> $30 \mathrm{DAI}$ ) followed by detached leaf methods $\mathrm{C}$ than those in other methods in which reduced turgidity of the leaves was recorded (Fig. 3).

For evaluating bioefficacy of EPF isolates against whitefly eggs/nymphs and adults, several laboratory bioassay techniques have been used in previous studies; however, leaf survival and tenderness, during bioassay for up to 7-15 days in cotton, have been the major concern for any successful bioassay, as the leaf survival and turgidity/tenderness are considered to be one of crucial factors for making leaf suitable for feeding and survival of sucking pests. Five laboratory bioassay methods reported in the past, and a new modified polyhouse bioassay method (NMPBM) were evaluated. Ibrahim et al. (2011) and Malekan et al. (2015) used detached tomato leaf for evaluating EPF isolates against Trialeurodes vaporariorum and B. tabaci. The cut petiole was covered by a small piece of cotton enriched by $2 \mathrm{ml} \mathrm{NP}$ solution, and placed on a filter paper wetted with distilled water in a Petri-dish. Mascarin (2013) evaluated EPF isolates against $B$. tabaci, using detached bean leaf as well as a leaf disc (3.8 cm diameter) up to 8 days on molten water agar $(1 \% w / v)$ in breeding discs. Similarly, Wraight et al. (2000, 2007) used excised leaves of Hibiscus rosa-sinensis L. (Malvaceae) for evaluation of EPF isolates against 


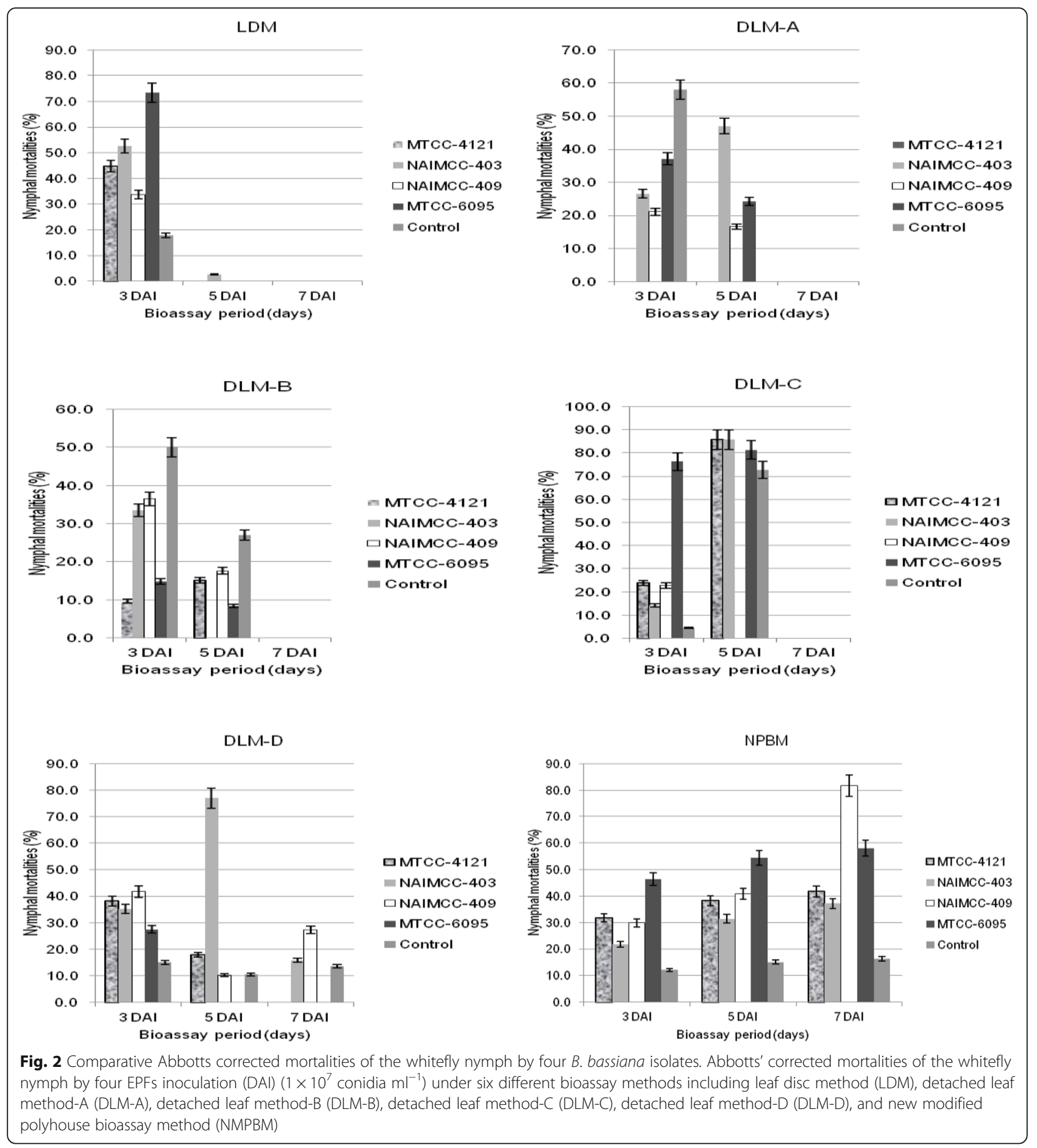

silverleaf whitefly. The leaves were transferred to large Petri-dishes, fitted with small reservoirs embedded in water-saturated cotton to hold the leaf petiole. The dishes were enclosed in plastic bags and placed in an incubator up to 8-10 days. Cuthbertson et al. (2005) and Eslamizadeh et al. (2015) also used 2-3-week-old excised leaves of Cucumis sativus L. for evaluating Paecilomyces fumosoroseus against B. tabaci. The leaves petioles were embedded in the cotton wool. Likewise, in IRAC susceptibility test method no. 8, plastic cups with a hole on the lower side to fit the leaf petiole into it were used for chemical pesticide bioassay against whitefly. Cut petiole was dipped into the outside water reservoir, and cups were covered by muslin clothes (IRAC 2009a). IRAC method no. 24 developed for evaluation of insecticides against Aphis gossypii on Gossypium hirsutum suggests 


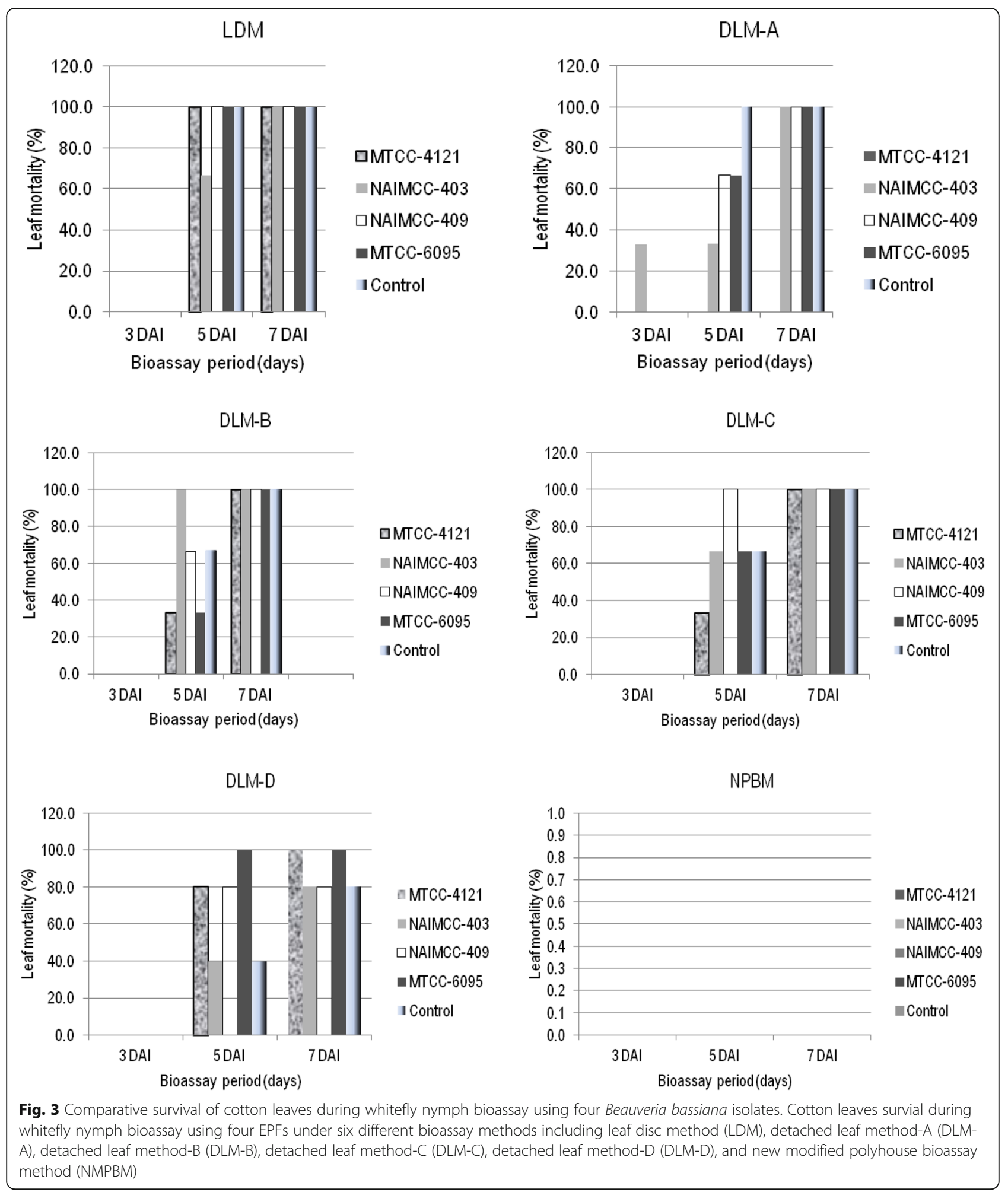

that cut leaf petiole should be inserted into the insecticide filled glass vials through the small cut in the parafilm (IRAC 2009c). After infestation, glass vial along with infested leaf are placed into the inner center of a large plastic container $(17 \mathrm{~cm}$ diameter $\times 6 \mathrm{~cm}$ height), which is coated with a thin layer of liquid Fluon using cotton wool.

In contrast to these previously reported methods, during the present study, cotton leaf discs and full leaf placed onto the $0.2 \%$ agar (leaf disc method and 
detached leaf method A) were not found suitable, because the leaf associated saprophytes (fungi/bacteria) began their growth on the media, leading to death of leaf from the third day onwards. Similarly, the cotton leaves remained healthy only up to 3-4 days, and subsequently the leaves lost turgidity leading to nymphal starvation in the detached leaf methods, where leaves were supported by $5 \mathrm{ml}$, and/or $15 \mathrm{ml} 0.2 \%$ sucrose solution (detached leaf method $\mathrm{B}$ and $\mathrm{C}$ ) and in a plastic tray method (detached leaf method D). The bioassay could not be performed up to 7 days in these leaf disc and detached leaf methods, except NMPBM (Figs. 1, 2, and 3). In NMPBM, leaf remained healthy, fresh without showing any turgidity change up to $30 \mathrm{DAI}$, and nymphal mortality was recorded in an increasing trend up to $7 \mathrm{DAI}$ (21.7 to $81.6 \%)$. Fully expanded, intact, and undamaged leaves in NMPBM provided a support to natural survival of the growing nymphs and to the fungal inoculum for causing infection. Hence, NMPBM technique was found to be more suitable and maintained leaf turgidity consistently than other methods. Even, the IRAC susceptibility test methods series no: 016 is almost similar to NMPBM for maintaining the leaf turgidity. However, this IRAC method seems to be more sophisticated, labor intensive, and requires a considerable space and time, because it is performed in cages that require considerably more labor, time, and expenses for trimming the leaves, using scissors, transferring the whitefly adults into cages, using aspirators, and for maintaining the potted plants in ventilated holding cages. Due to this reason, it may not be more suitable and easy for a large-scale evaluation of EPF isolates than NMPBM. Unlike this method, NMPBM is easy, less time consuming, and less labor intensive in terms of whitefly egg laying, marking, and recording the nymphal observations during the bioassay periods than those with others. The health and survival of cotton leaf even up to 30 days could further be utilized for evaluation of residual effect of fungal inoculum/pesticides. Therefore, NMPBM was used for evaluating EPF strains against whitefly nymphs (Fig. 1). Moreover, the IRAC method no: 016 was recommended for evaluation of insecticides against the whitefly eggs and nymphs (IRAC 2009b), while the NMPBM can be used for screening of both EPF isolates as well as chemical/botanical insecticides.

\section{Evaluation of EPF isolates against whitefly nymphs}

The results of the experiments conducted to evaluate virulence of EPF isolates using NMPBM showed that the significantly highest $(\mathrm{CD}$ at $5.04 ; P<0.05)$ nymphal mortality at 7 DAI was recorded in Bb-4511 (95.1\%), Bb-4565 (89.9\%), and Ma-1299 (86.7\%). Among ten EPF isolates, the highest mycelial growth (CD 8.23 at $P<$ 0.05) was recorded in $\mathrm{Cj}-089, \mathrm{Cj}-102$, and Fm-083 compared to other obtained EPF isolates from culture collection centres. Though, the highest conidia $\mathrm{ml}^{-1}\left(1 \times 10^{8}\right)$ was recorded in Bb-409, Bb-4511, and Fm-083 than others EPF isolates (CD 10.23 at $P<0.05)$. However, based on the overall bioefficacy index, the Bb-4511 (78.1\%), Cj-102 (77.0\%), and Cj-089 (75.4\%) (CD 4.03 at $P<0.05)$ were found to be the best performing EPF isolates (Table 3).

Table 3 Comparative mycelia growth, spore production, mortality of whitefly nymphs, and bioefficacy index of entomopathogenic fungal isolates

\begin{tabular}{|c|c|c|c|c|c|c|}
\hline \multirow{2}{*}{$\begin{array}{l}\text { Treatments } \\
\text { (isolates) }\end{array}$} & \multirow{2}{*}{$\begin{array}{l}\text { Mycelial } \\
\text { growth }^{a}\end{array}$} & \multirow{2}{*}{$\begin{array}{l}\text { Spore } \\
\mathrm{ml}^{-1} \\
\left(10^{7}\right)^{b}\end{array}$} & \multicolumn{3}{|c|}{ Percent corrected mortality over control $\left(1 \times 10^{6}\right)^{c}$} & \multirow{2}{*}{$\begin{array}{l}\text { Biological } \\
\text { efficacy } \\
\text { index }^{d}\end{array}$} \\
\hline & & & $3 \mathrm{DAl}^{* *}$ & 5DAl & 7DAl & \\
\hline C. javanica-089 & $81.0 \mathrm{a}$ & $54.7 \mathrm{~cd}$ & 42.4 (40.6)de & $73.9(59.3) \mathrm{cd}$ & $77.6(61.8) c$ & $75.4 \mathrm{a}$ \\
\hline C. javanica-102 & $80.1 a$ & $56.6 \mathrm{bd}$ & 38.6 (38.4)def & 61.7 (51.8)e & $81.0(64.2) b$ & $77.0 \mathrm{a}$ \\
\hline F. moniliforme-083 & $76.5 \mathrm{ab}$ & $63.3 a b c$ & $42.0(40.4) \mathrm{de}$ & $76.3(60.9) \mathrm{bc}$ & $76.7(61.1) c$ & $74.6 a b$ \\
\hline C. javanica-099 & $69.7 \mathrm{bc}$ & $34.7 e$ & $49.3(44.6) c d$ & $78.3(62.2) \mathrm{bc}$ & $81.1(64.2) b$ & $70.2 \mathrm{~cd}$ \\
\hline M. anisopliae-1299 & $64.0 c$ & $34.9 e$ & $77.4(61.6) a$ & $82.7(65.4) a b$ & 86.7 (68.6)ab & $71.0 \mathrm{bc}$ \\
\hline B. bassiana-409 & $64.0 \mathrm{c}$ & $69.9 a$ & $20.3(26.8) f$ & 62.1 (52.0)e & $78.2(62.2) \mathrm{c}$ & $72.0 \mathrm{bc}$ \\
\hline B. bassiana -4565 & $62.4 \mathrm{C}$ & 14.7 & $57.2(49.1) \mathrm{bcd}$ & $76.6(61.1) b c$ & 89.9 (71.5)a & 69.1de \\
\hline B. bassiana-4511 & $59.3 c d$ & 65.3ab & 75.0 (60.0)ab & 88.6 (70.3)a & $95.1(77.2)$ & $78.1 \mathrm{a}$ \\
\hline B. bassiana- 6097 & $51.7 d$ & 43.9e & 23.6 (29.1)ef & $64.4(53.4) \mathrm{de}$ & 81.7 (64.7)bc & $65.5 \mathrm{e}$ \\
\hline B. bassiana-4543 & $50.3 d$ & $58.6 b$ & 67.4 (55.2)abc & 80.0 (63.4)bc & 85.4 (67.5)ab & 69.1de \\
\hline $\mathrm{CD}$ at $(P<0.05)$ & 8.23 & 10.23 & 11.97 & 6.05 & 5.04 & 1.04 \\
\hline Variance & 24.15 & 41.21 & 43.33 & 36.64 & 25.39 & 4.12 \\
\hline
\end{tabular}

**Mean values followed by the same letter are not significantly different from each other at $(P<0.05)$

${ }^{a}$ Mycelial growth diameter was measured (in $\mathrm{mm}$ ) at 10 days post inoculation (DAI) from the Petri plates

${ }^{\mathrm{b}}$ The spore concentration per milliliter was measured at 10 DAl using $5 \mathrm{~mm}$ mycelial disc from the Petri plates

${ }^{c}$ Figure in parenthesis are arcsign transformed values of percent nymphal mortality (2nd to 3rd nymphal instars)

${ }^{\mathrm{d}}$ Biological efficacy index $(\mathrm{Bl})=$ mycelia growth $(\mathrm{mm})$, sporulation $\left(1 \times 10^{7}\right.$ conidia $\left.\mathrm{ml}^{-1}\right)$; nymphal mortality at $7 \mathrm{DAl}(\%) ; \mathrm{BI}=35(\mathrm{MG})+15(\mathrm{SP})+50(\mathrm{MO}$ at $7 \mathrm{DAl})$ 
Table 4 Summary of probit analysis of binomial proportion and calculated lethal concentration of concentration-mortality response $\left(\mathrm{LC}_{50}\right.$ and $\left.\mathrm{LC} 90\right)$

\begin{tabular}{lllllll}
\hline EPF isolates & $\mathrm{LC}_{50}(95 \% \mathrm{FL})^{\mathrm{a}}$ & $\mathrm{LC}_{90}(95 \% \mathrm{FL})^{\mathrm{b}}$ & Intercept $\pm \mathrm{SE}^{\mathrm{C}}$ & $\mathrm{Slope} \pm \mathrm{SE}^{2 \mathrm{~d}}(\mathrm{df}=3)$ & $P$ value $\left(X^{2}\right)$ \\
\hline C. javanica-089 & $0.22 \times 10^{4}\left(0.11 \times 10^{4}-0.34 \times 10^{4}\right)$ & $0.99 \times 10^{8}\left(0.87 \times 10^{8}-1.12 \times 10^{8}\right)$ & $4.19 \pm 2.12$ & $2.47 \pm 0.33$ & 65.99 & $<0.001$ \\
C. javanica-102 & $0.64 \times 10^{4}\left(0.59 \times 10^{4}-0.69 \times 10^{4}\right)$ & $1.17 \times 10^{8}\left(1.05 \times 10^{8}-1.28 \times 10^{8}\right)$ & $3.48 \pm 3.62$ & $2.73 \pm 0.56$ & 29.01 & $<0.001$ \\
F. moniliforme-083 & $0.64 \times 10^{5}\left(0.59 \times 10^{5}-0.69 \times 10^{5}\right)$ & $1.19 \times 10^{8}\left(1.07 \times 10^{8}-1.32 \times 10^{8}\right)$ & $3.59 \pm 3.56$ & $2.56 \pm 0.55$ & 49.02 & $<0.001$ \\
C. javanica-099 & $1.01 \times 10^{6}\left(0.89 \times 10^{6}-1.32 \times 10^{6}\right)$ & $1.71 \times 10^{8}\left(1.44 \times 10^{8}-1.99 \times 10^{8}\right)$ & $3.24 \pm 5.27$ & $2.44 \pm 0.72$ & 130.45 & $<0.001$ \\
M.anisopliae-1299 & $0.64 \times 10^{5}\left(0.59 \times 10^{5}-0.68 \times 10^{5}\right)$ & $1.12 \times 10^{8}\left(1.02 \times 10^{8}-1.22 \times 10^{8}\right)$ & $3.42 \pm 3.61$ & $2.83 \pm 0.56$ & 47.79 & $<0.001$ \\
B. bassiana-409 & $2.44 \times 10^{6}\left(1.35 \times 10^{6}-3.54 \times 10^{6}\right)$ & $4.18 \times 10^{8}\left(2.08 \times 10^{8}-6.28 \times 10^{8}\right)$ & $3.03 \pm 8.49$ & $2.12 \pm 0.93$ & 178.20 & $<0.001$ \\
B. bassiana-4565 & $0.65 \times 10^{5}\left(0.55 \times 10^{5}-0.75 \times 10^{5}\right)$ & $1.78 \times 10^{8}\left(1.32 \times 10^{8}-2.25 \times 10^{8}\right)$ & $4.06 \pm 3.24$ & $1.85 \pm 0.51$ & 69.65 & $<0.001$ \\
B. bassiana-4511 & $0.52 \times 10^{4}\left(0.48 \times 10^{4}-0.57 \times 10^{4}\right)$ & $1.01 \times 10^{8}\left(0.93 \times 10^{8}-1.10 \times 10^{8}\right)$ & $3.69 \pm 3.01$ & $2.74 \pm 0.48$ & 36.52 & $<0.001$ \\
B. bassiana-6097 & $4.91 \times 10^{6}\left(0.6 \times 10^{6}-10.48 \times 10^{6}\right)$ & $8.74 \times 10^{8}\left(1.72 \times 10^{8}-19.20 \times 10^{8}\right)$ & $3.12 \pm 9.78$ & $1.89 \pm 0.99$ & 147.53 & $<0.001$ \\
B. bassiana-4543 & $0.99 \times 10^{6}\left(0.89 \times 10^{6}-1.10 \times 10^{6}\right)$ & $1.61 \times 10^{8}\left(1.39 \times 10^{8}-1.82 \times 10^{8}\right)$ & $3.02 \pm 5.06$ & $2.81 \pm 0.70$ & 323.48 & $<0.001<$ \\
\hline
\end{tabular}

Values are means of two experiments with three replications for each EPF isolates with each concentration against 50 whitefly nymphs in each replicate. The

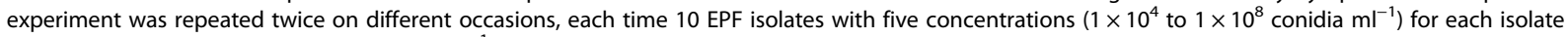
${ }^{a}$ The concentrations presented are conidia $\mathrm{ml}^{-1}$ and whitefly nymphs (second to third nymphal instars)

${ }^{\mathrm{b}} \mathrm{FL}=$ fiducial limits; $\mathrm{DF}=$ number of terms (i.e., concentrations) used for the regression minus

${ }^{\mathrm{c}} \mathrm{SE}=$ standard error of the fungal concentrations

${ }^{\mathrm{d}}$ Likelihood ratio $\times 2$ test statistic indicates a satisfactory goodness-of-fit of empirical data compared to the estimated regression line

Generally, second nymphal instars of B. tabaci were found to be the most susceptible stage, while the adult ranked second (Cuthbertson et al. 2005). B. bassiana is reported to cause B. tabaci nymphal mortality from 76.7 to $91.6 \%$ and up to $100 \%$ in adults at $1 \mathrm{mg} \mathrm{m}^{-1}$ (Faria and Wraight 2001). Average nymphal mortality up to $25.7 \%$ at 7 DAI was reported; however, at 14 DAI, it ranged from 6.1 to $92.3 \%$ in a melon leaves bioassay method (Vicentini et al. 2001). Different isolates of $B$. bassiana caused (3-85\%) mortality to the fourth instar nymphs $\left(10^{7}\right.$ conidia $\left.\mathrm{ml}^{-1}\right)$ (Quesada-Moraga et al. 2006). The efficacy of $L$. lecanii isolates were reported to be similar to $B$. bassiana in reducing whitefly population in tomato crops, ranging from 56 to $87 \%$ with the max-

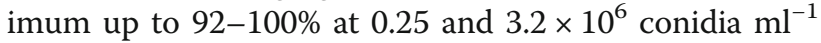
(Karthikeyan and Selvanarayanan 2011).

\section{Concentration-mortality and time-mortality bioassay}

All the EPF isolates were pathogenic to whitefly nymphs. Increased EPF concentrations resulted to increase the mortality (Table 4). The $\mathrm{LC}_{50}$ values of selected EPF strains ranged from $0.22 \times 10^{4}(\mathrm{Cj}-089)$ to $4.91 \times 10^{6}$ (Bb-6097) conidia $\mathrm{ml}^{-1}$, while the $\mathrm{LC}_{90}$ values ranged between $0.99 \times 10^{8}(\mathrm{Cj}-089)$ and $8.74 \times 10^{8}(\mathrm{Bb}-6097)$ conidia $\mathrm{ml}^{-1}$ at $3 \mathrm{DAI}$, with $10^{4}$ conidia $\mathrm{ml}^{-1}$. The lowest $\mathrm{LC}_{50}$ and $\mathrm{LC}_{90}$ values were recorded by $\mathrm{Cj}-089$ and $\mathrm{Bb}-4511$ than other EPF isolates, respectively.

Similarly, the isolates of $B$. bassiana and Isaria fumosorosea were reported to be virulent against $B$. tabaci nymphs (71-86\% mortality within 8 days), with $\mathrm{LT}_{50}$ values ranging from 3 to 4 DAI with $10^{7}$ conidia $\mathrm{ml}^{-1}$ (Mascarin 2013). Obtained results showed that there was a variable response of the EPF isolates to mycelical growth, sporulation, and nymphal mortality.
The local isolates had faster and higher mycelial growth than those in the EPF isolates obtained from culture collection centres. This can be due to their adaptation to prevailing environmental conditions (Sevim et al. 2012). Based on the overall bioefficacy index, including the mycelia growth, sporulation along with the mortalities, the best performing EPF isolates during the study were found to be the Bb-4511, $\mathrm{Cj}-102$, and $\mathrm{Cj}-089$. The lowest $\mathrm{LC}_{50}$ and $\mathrm{LC}_{90}$ values were recorded by $\mathrm{Cj}-089$ and $\mathrm{Bb}-4511$ than other EPF isolates. The identified most virulent EPF isolates with best bioefficacy index will have better potential for utilization in IRM in B. tabaci.

\section{Conclusion}

The present study showed that the NMPBM can play an important role in evaluating large numbers of EPF isolates, and to find out the most virulent ones. The overall bioefficacy index of EPF isolates should be considered for selecting a virulent EPF for field success, nymphal morality is not only the single factor. The identified most virulent EPF isolates with best bioefficacy index could be utilized further for development of eco-compatible and effective bioformulations. The field deployment of these formulations, as an alternative to chemical pesticide or as an IPM/ IRM component, might help in reducing whitefly population as well as CLCuD incidence.

\section{Acknowledgements}

The authors are thankful to Central Institute for Cotton Research, Regional Station, Sirsa under Indian Council of Agricultural Research, New Delhi for providing necessary laboratory and field facilities and funding during the course of the investigation.

Funding

Not applicable. 


\section{Availability of data and materials}

All data generated or analyzed during this study are included in this published article

\section{Authors' contributions}

All authors equally contributed for the designing of experiments. SKS has the major contribution in conducting the experiments and in writing the manuscript. All authors read and approved the final manuscript.

\section{Authors' information}

SKS is the Senior Scientist (Plant Pathology) and having about 18 years of experience in conducting research on biological control.

DM is the Principal Scientist (Plant Pathology) and Head, ICAR-CICR Regional station, Sirsa and having more than 30 years of experience.

RK is the Principal Scientist (Entomology) and having about 20 years of experience.

SK is the Principal Scientist (Entomology) and Head Crop Protection Division, ICAR-CICR; she is having about 25 years of experience.

KRK is the Ex Director CICR and presently he is Head, Technical Information Section, International Cotton Advisory Committee

\section{Ethics approval and consent to participate}

Not applicable.

\section{Consent for publication}

Not applicable.

\section{Competing interests}

The authors declare that they have no competing interests.

\section{Publisher's Note}

Springer Nature remains neutral with regard to jurisdictional claims in published maps and institutional affiliations.

\section{Author details}

'ICAR- Central Institute for Cotton Research, Regional Station, Sirsa, Haryana, India. ${ }^{2}$ CAR-Central Institute for Cotton Research, Nagpur, Maharashtra, India. ${ }^{3}$ Technical Information Section of International Cotton Advisory Committee (ICAC), Washington D.C., USA.

Received: 22 January 2019 Accepted: 12 April 2019

Published online: 17 May 2019

\section{References}

Abbott WS (1925) A method of computing the effectiveness of an insecticide. Econ Entomol 18:265-267

Anonymous (2019) Central insecticides board and registration committee. http:// ppqs.gov.in/divisions/cib-rc/about-cibrc. Accessed 2 Oct 2018

Basit MS, Saeed MA, Saleem I, Denholm SM (2013) Detection of resistance, crossresistance, and stability of resistance to new chemistry insecticides in Bemisia tabaci (Homoptera: Aleyrodidae). J Econ Entomol 106:1414-1422

Cuthbertson AGS, Walters KFA, Carola D (2005) Compatibility of the entomopathogenic fungus Lecanicillium muscarium and insecticides for eradication of sweet potato whitefly, Bemisia tabaci. Mycopathologia 160:35-41

Eslamizadeh R, Said A, Sajap B, Omar DB, Binti NA, Dam A (2015) Evaluation of different isolates of entomopathogenic fungus, Isaria fumosoroseus (Deuteromycotina: Hyphomycetes) against Bemisia tabaci (Hemiptera: Aleyrodidae). Biol PI Protec 2:82-90

Faria M, Wraight SP (2001) Biological control of Bemisia tabaci with fungi. Crop Prot 20:767-778

Finney DJ (1952) Probit analysis, 2nd edn. University Press, Cambridge, p 318

Hsieh CH, Wang CH, Ko CC (2006) Analysis of Bemisia tabaci (Hemiptera: Aleyrodidae) species complex and distribution in Eastern Asia based on mitochondrial DNA markers. Ann Entomol Soc Am 99:768-775

Huang X, Madan A (1999) CAP3: a DNA sequence assembly program. Genome Res 9:868-877

Humber RA (2012) Identification of entomopathogenic fungi. In: Lacey LA (ed) Manual of techniques in invertebrate pathology. Academic, London, pp 151-187
Ibrahim L, Hamieh A, Ghanem H, Ibrahim SK (2011) Pathogenicity of entomopathogenic fungi from Lebanese soils against aphids, whitefly and non-target beneficial insects. Int J Agri Sci 3:156-164

IRAC (2009a) Susceptibility test methods series method no:008 version:3. https:// www.irac-online.org/methods/bemisia-tabaci-adults/

IRAC (2009b) Susceptibility test methods series method no:016 version:3. https:// www.irac-online.org/methods/trialeurodes-vaporariorum-bemisia-tabacinymphs/

IRAC (2009c) Susceptibility test methods series method no024 version1. https:// www.irac-online.org/methods/aphis-gossypii-nymphs/

Jones DR (2003) Plant viruses transmitted by whiteflies. European J PI Patho 109: $195-219$

Karthikeyan A, Selvanarayanan V (2011) In vitro efficacy of Beauveria bassiana (Bals.) Vuill. and Verticellium lecanii (Zimm.) Viegas against selected insect pest of cotton. Recent Res Sci Technol 3:142-143

Kranthi KR (2015) Whitefly-the black story. Cotton Statistics and News. No. 23. Cotton Association of India. 23rd issue, 8 September 2015. http://www. caionline.in/site/publications

Lacey LA, Grzywacz D, Shapiro-llan DI, Frutos R, Brownbridge M, Goettel MS (2015) Insect pathogens as biological control agents: back to the future. $J$ Invertebr Pathol 132:1-41

Lacey LA, Wraight SP, Kirk AA (2008) Entomopathogenic fungi for control of Bemisia tabaci biotype B: foreign exploration, research and implementation. In: Gould J, Hoelmer H, Goolsby J (eds) Classical biological control of Bemisia tabaci in the United States-a review of interagency research and implementation, progress in biological control, vol 4. Springer, Dordrecht, pp 33-69 https://doi.org/10.1007/978-1-4020-6740-2_3

Malekan A, Hatami B, Ebadi R, Akhavan A, Radjab R (2015) Evaluation of entomopathogenic fungi Beauveria bassiana and Lecanicillium muscarium on different nymphal stages of greenhouse whitefly Trialeurodes vaporariorum in greenhouse conditions. Biharean Biolo 9:108-112

Mascarin GM (2013) The virulence of entomopathogenic fungi against Bemisia tabaci biotype B (Hemiptera: Aleyrodidae) and their conidial production using solid substrate fermentation. Biol Control 66:209-218

Monga D (2014) Cotton leaf curl virus diseases. Central Institute for Cotton Research, Regional Station, Sirsa, pp 343-360

Naveen NC, Chaubey R, Kumar D, Rebijith KB, Rajagopal R, Subrahmanyam B, Subramanian S (2017) Insecticide resistance status in the whitefly, Bemisia tabaci genetic groups Asia-I, Asia-II-1 and Asia-II-7 on the Indian subcontinent. Sci Rep 7:40634 https://doi.org/10.1038/srep40634

Quesada-Moraga E, Maranhão EA, Valverde-Garcia P, Santiago-Álvarez C (2006) Selection of Beauveria bassiana isolates for control of the whiteflies Bemisia tabaci and Trialeurodes vaporarium on the basis of their virulence, thermal requirement and toxicogenic activity. Biol Control 36:274-287

Sadeh D, Nitzan N, Shachter A, Chaimovitsh D, Dudai N, Ghanim M (2017) Whitefly attraction to rosemary (Rosmarinus officinialis L.) is associated with volatile composition and quantity. PLoS One 12(5):e0177483 https://doi.org/ 10.1371/journal.pone.0177483

Sain SK, Monga D, Kumar R, Nagrale D, Kranthi S (2017) Studies to identify most virulent strains of entomopathogenic fungi for microbial control of sweet potato whitefly (Bemisia tabaci) infesting cotton in North India. In: Venugopalan et al (eds) $7^{\text {th }}$ Asian Cotton Research \& Development Network Meeting, Production of quality fibre and doubling cotton farmers' income, Indian Society for Cotton Improvement, Mumbai, India, p 21

Scorsetti AC, Gregorio C, De L'p, Lastra CC (2008) New records of entomopathogenic fungi infecting Bemisia tabaci and Trialeurodes vaporariorum, pests of horticultural crops. Argentina Bio Control 53:787-796

Sevim A, Hofte M, Demirbag Z (2012) Genetic variability of Beauveria bassiana and Metarhizium anisopliae var. anisopliaeisolates obtained from the Eastern Black Sea region of Turkey. Turk J Biol 36:255-265

Sheoran OP, Tonk DS, Kaushik LS, Hasija RC, Pannu RS (1998) Statistical software package for agricultural research workers. In: Hooda DS, Hasija RC (eds) Recent advances in information theory, statistics and computer applications, department of mathematics statistics, CCS HAU, Hisar, India, pp 139-143

Vicentini S, Faria M, De Oliveira RVM (2001) Screening of Beauveria bassiana (Deuteromycotina: Hyphomycetes) isolates against nymphs of Bemisia tabaci (Genn.) biotype B (Hemiptera: Aleyrodidae) with description of a bioassay method. Neotrop Entomol 30:97-103

White TJ, Bruns T, Lee S, Taylor JW (1990) Amplification and direct sequencing of fungal ribosomal RNA genes for phylogenetics. In: Innis MA, Gelfand DH, 
Sninsky JJ, White TJ (eds) PCR protocols: a guide to methods and applications. Academic Press Inc, New York, pp 315-322

Wraight SP, Carruthers RI, Jaronski ST, Bradley CA, Garza CJ, Wraight GS (2000) Evaluation of the entomopathogenic fungi Beauveria bassiana and Isaria fumosoroseus for microbial control of the silverleaf whitefly, Bemisia argentifolii. Biol Control 17:203-217

Wraight SP, Inglis GD, Goettel MS (2007) Fungi. In: Lacey LA, Kaya HK (eds) Field manual of techniques in invertebrate pathology: application and evaluation of pathogens for control of insects and other invertebrate pests. Springer, Dordrecht, pp 223-248

\section{Submit your manuscript to a SpringerOpen ${ }^{\circ}$ journal and benefit from:}

- Convenient online submission

- Rigorous peer review

- Open access: articles freely available online

High visibility within the field

- Retaining the copyright to your article

Submit your next manuscript at $\boldsymbol{\sim}$ springeropen.com 